\title{
Laser-based magnetic micro-inscription: surface heating versus deep penetration regime
}

\author{
Marko Pogačar, ${ }^{1, *}$ Matija Jezeršek ${ }^{2}$ \\ ${ }^{1}$ RLS Merilna Tehnika d.o.o, 1218 Komenda, Slovenia \\ ${ }^{2}$ Faculty of Mechanical Engineering, University of Ljubljana, 1000 Ljubljana, Slovenia \\ *Corresponding author: marko.pogacar@rls.si
}

\begin{abstract}
The technology of magnetic micro-inscription can be used for in-axis positioning measurements directly from a linear actuator which reduces the cost and size of the whole system. In this paper, two different regimes for laser- based magnetic micro-inscription were compared: a surface heating and a deep penetration heating. The first regime is the same as conductive heating and the second is similar to the process of keyhole welding. The experimental results show that both processes can be effectively stabilized by means of controlling the width and depth of the microstructure transformation cross-section, as they are able to compensate for external disturbances, such as higher roughness, and the gradual accumulation of heat. From numerical analysis it could be seen that the perfect inscription should have depth equal or more than 0.8 of period of inscription and width around $0.80 \pm 0.05$ of period which is not achievable with the surface heating regime, but only with the deep penetration regime. Results show that the deep penetration heating requires 5 -times less laser energy which leads to lower heat accumulation and a more stable process, is unaffected by disturbances, such as higher roughness, and provides an almost $15 \%$ higher relative amplitude as measured by the reference magnetic sensor.
\end{abstract}

Magnetic inscription; surface heating; deep penetration heating; adaptive laser power control; microstructure transformation; magnetic encoder;

\section{INTRODUCTION}

A structured magnetic micro-inscription is used as position information for magnetic encoders [1]. It was developed for in-axis position measurement where a magnetic code is inscribed directly onto a steel shaft [2]. With this approach multiple functionalities can be integrated into one device, such as linear actuator with an in-axis position measurement capability, in order to build smarter and lighter devices. The motivation is to replace the conventional method of making the magnetic inscription by turning the grooves in high permeability carbon-steel and filling them with nonmagnetic material with innovative laser-based magnetic inscription [3]. The problem of the conventional method is that it consist of multiple operations which are time and cost consuming. On the other hand, the challenges of laser-based magnetic inscription are in workpiece preparation, maintaining repeatability of shape of marks, ensuring immunity to disturbances, e.g. different roughness, laser energy consumption and position accuracy of inscription.

The basis of the magnetic inscription is a local microstructure transformation in austenitic stainless steel (e.g. AISI 304L). Firstly, a large thermo-mechanical stress is induced to result in microstructure transformation from non-magnetic ( $\gamma$ austenite) to magnetic ( $\alpha$ ' martensite) phase [4]. Secondly, highly intensive laser illumination is applied in order to locally increase the material temperature to induce the reverse transformation back to original non-magnetic phase [5]. With this approach, a magnetically coded steel bar can be produced. If the coded bar is placed in a uniform magnetic field, the magnetic field is modulated according to the magnetic inscription. Modulation can be read with a magnetic sensitive sensor, such as a magnetic encoder apparatus with Hall elements [6]. It is known that the modulation strength (i.e. the signal amplitude on the sensor device) depends on the distance from the sensor to the magnetic code, the strength of the magnetic field, the period and the cross-section shape of the transformed region.

In this study we have first focused on the optimization of the shape of the transformed region which is also called a mark. Semicircular and U- shaped marks were numerically investigated in order to achieve the highest signal amplitude on a simulated magnetic sensor. The numerical results were further experimentally tested by laser- based local microstructure transformation. Different cross-section shapes were achieved by varying laser parameters, such as laser power, processing speed and laser-beam diameter. Consequently two different processing regimes of laser-material interaction were performed. The first one is a surface heating $(\mathrm{SH})$ regime, where surface temperature does not exceed evaporation. The second is a so-called deep penetration heating (DPH) regime, where much higher laser light intensity induces the generation of a keyhole, well-known in laser welding applications [7]. Both regimes were experimentally compared using a metallographic analysis, energy consumption, disturbance immunity, response time and by means of the signal amplitude and the position noise measured by a reference magnetic encoder apparatus LinACE ${ }^{\mathrm{TM}}$ sensor which is described in [6].

\section{NUMERICAL METHODS}

A numerical analysis of the static magnetic field was performed to ascertain the best theoretical proportion of cross-section shape of transformed regions (marks) in terms of that the highest signal amplitude of LinACE'M sensor could be achieved . In the scope there was the mark width against the period and the depth of marks against the period. 
The software for numerical simulation was femm 4.2, which is based on the finite element method. The problem type was planar (2D), the accuracy of solution was $10^{-8}$, while successive approximation was chosen as the AC solver method. The mesh size in the scope of observing was $0.01 \mathrm{~mm}$, elsewhere 1.0 $\mathrm{mm}$. The geometry of the magnet was $4 \times 14 \mathrm{~mm}$ (height $x$ length), the steel bar had a diameter of $4 \mathrm{~mm}$ and a length of $36 \mathrm{~mm}$. Marks had a fixed period (P) of $0.60 \mathrm{~mm}$. Material properties were taken from femm library: magnet - SmCo $27 \mathrm{MGOe}$, environment - Air, steel bar -AISI 430 . The actually used steel AISI304L in experiments have original austenitic nonmagnetic phase and could not be used for simulation. In preliminary experiment we compare amplitude response on magnetic sensor of cryogenic cold worked steel AISI 304L and steel AISI 430 and on both we inscribed positional information by turning the groves (similar like marks). The results show a good matching between amplitude responses on magnetic sensor.

The object geometry used for numerical simulation was parametrically generated in a program written in Matlab 2016b. Also the results of magnetic modulation were processed in Matlab where, for the purpose of amplitude information, the LinACE ${ }^{\mathrm{TM}}$ sensor was modeled based on the reference [6]. Both programs, Matlab and Femm, were live linked.

Two different types of marks were simulated: semi-circular and $U$ - shaped (see Figure 1). Semicircular shape is basic geometry shape and represents a good approximation with marks made by laser surface heating process, $\mathrm{U}$ - shape is very close to real shape of cross section of deep penetration heating regime (see Figure 5). U-shape marks were modeled as semicircular plus rectangular shape in order to achieve higher depth. During these simulations, the period (P) between marks remained constant at $0.60 \mathrm{~mm}$. The goal was to achieve the highest possible amplitude of signal on the distance of $0.20 \mathrm{~mm}$ above the steel bar (see Figure 2) which is equal to the air gap between the real magnetic sensor and the specimen.
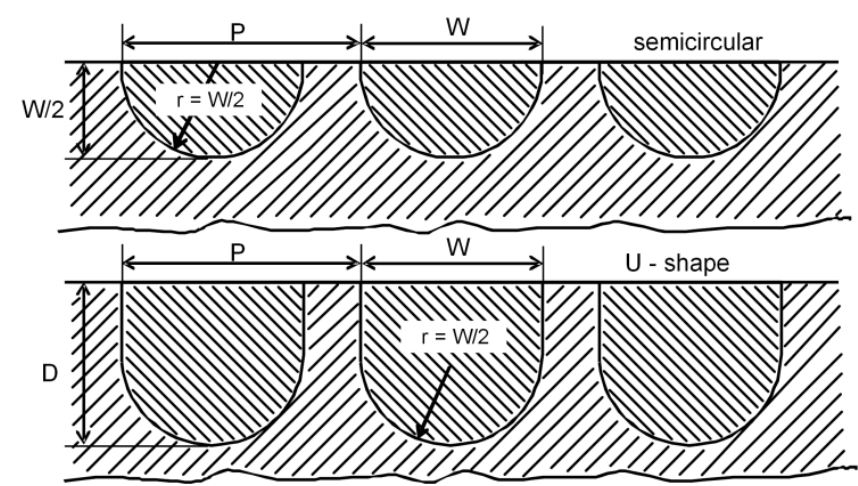

Figure 1: Different shape of transformed regions (marks) used for numerical investigation with geometrical parameters: $P-$ period, $W-$ width and D- depth.

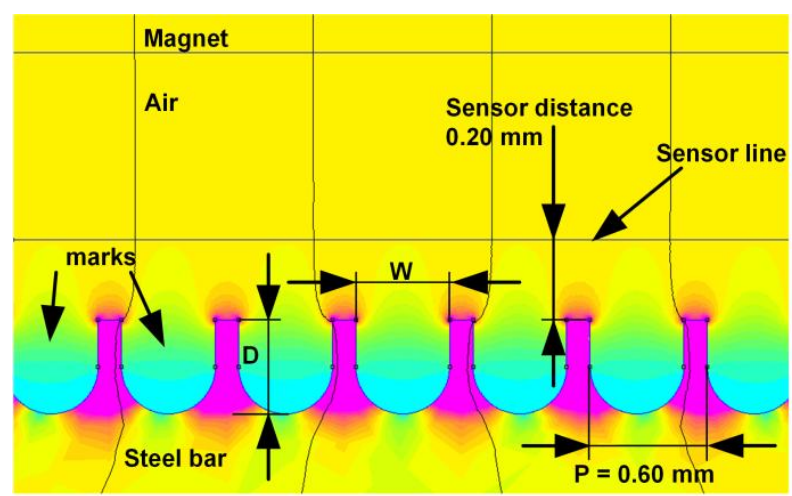

Figure 2: Typical result of simulated magnetic field using U-shape marks and colored representation of density field.

Simulations were done for width per period (W/P) ratios in the range from 0.1 to 1.0 and for depth per period (D/P) ratios from 0.1 to 1.0 . Step in both directions was 0.05 . Due-to definition of U-shape marks (semicircular + rectangular deepening), the minimum depth of shape of the marks at certain width is half of its width and basically represents semicircular marks.

Results of numerical simulation are shown on Figure 3 where the amplitude response is represented with a colour map. Blue colour represents the lowest amplitude responses which are at low ratio of $\mathrm{W} / \mathrm{P}<0.3$ and very high ratio $\mathrm{W} / \mathrm{P}>0.95$ no matter on $\mathrm{D} / \mathrm{P}$ ratio. The highest amplitudes, which are shown with dark red colour, are in the range of $W / P=0.80 \pm 0.05$ at $D / P>0.8$. These results clearly show that the optimal geometry of mark cross-section is not semicircular (see bottom inclined boundary of results on Fig. 3), but rather U-shape geometry. The calculated difference between maximal amplitudes for both geometries is approximately $16 \%$ in favor of the U-shape. 


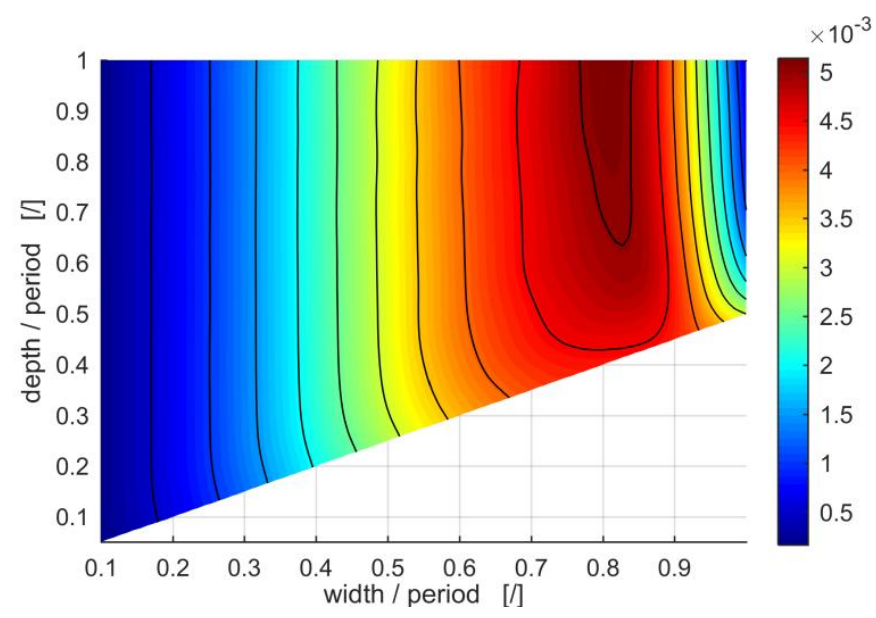

Figure 3: Contour graph of the calculated magnetic field amplitude as a function of width/period and depth/period ratios of mark crosssection. The highest value (dark red) represents the optimal geometry.

\section{EXPERIMENTAL METHODS}

\subsection{The experimental system}

The experimental system is shown in Figure 4. It consists of a fiber laser (IPG, YLR-400-AC) with a collimated exit beam ( 5 mm diameter) which is focused by a lens $(\mathrm{f}=41 \mathrm{~mm}$ ) towards the specimen's surface. Laser has a wavelength $1070 \mathrm{~nm}$ and a power of $400 \mathrm{~W}$ which can be modulated from continuous wave up to $50 \mathrm{kHz}$ with $10 \mu$ s rise time. InGaAs photodiode (PD) (Thorlabs, PDA 10D) is used as a feedback sensor for laser power control. The PD (with a spectral sensitivity range from $1200 \mathrm{~nm}$ to $2600 \mathrm{~nm}$ ) measures the power of the emitted light, which is proportional to the fourth power of the processing area's temperature. The electrical signal from PD was digitized using a control card and further conditioned with PID control logic to control the laser power. Output from control card is voltage signal from 0 to $10 \mathrm{~V}$ which regulates the laser power from 0 to $400 \mathrm{~W}$. For additional monitoring an oscilloscope Keysight 3034A (350 MHz bandwidth, max. sample rate $4 \mathrm{GS} / \mathrm{s}$ ) was used. More details of experimental setup could be found in reference [1].

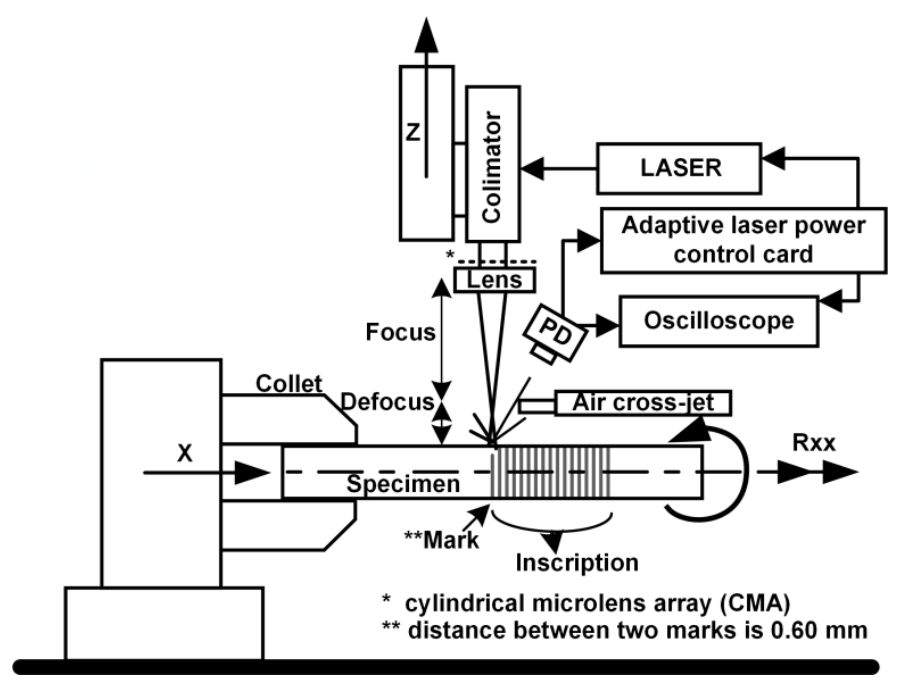

Figure 4: The experimental system for laser based magnetic micro-inscription on a steel bar

The specimen is held by a collet attached to a rotational holder. The other side of the specimen is fixed by a gripper which is free to rotate. Air cross-jet is used for the extraction of the laser-generated plume.

For the first set of experiments, a cylindrical microlens array (CMA) with 250- $\mu \mathrm{m}$ pitch and $5^{\circ}$ divergence angle (Edmund Optics) was installed between the collimator and the focusing lens. The CMA generates multiple focusing points in a line which is set perpendicularly to the specimen axis. In the second set, the CMA was removed in order to increase the laser peak power density. 


\subsection{Specimen}

The chemical composition of the specimen (AISI $304 \mathrm{~L}$ ) used in this investigation is presented in Table 1. The specimens were first cooled down to a temperature of $-196{ }^{\circ} \mathrm{C}$ and then immediately cold drawn with a strain rate of $8.3 \mathrm{~s}^{-1}$. The bar produced in this way consisted of approximately $60 \%$ martensite. The end diameter of the specimens was $8.67 \mathrm{~mm}$, length $150 \mathrm{~mm}$ and had a constant roughness ( $R a=0.22 \mu \mathrm{m}$ ). On one side of the specimen, additional rougher grinding was performed to achieve higher roughness (Ra $=0.60 \mu \mathrm{m}$, measured with Mitutoyo SURFTEST SJ-210). More detailed preparation of the specimen is described in references [1,4].

Table 1: Chemical composition of the austenitic bar AISI $304 \mathrm{~L}$

\begin{tabular}{|l|l|l|l|l|l|l|l|l|}
\hline C [\%] & Si [\%] & $\mathrm{Mn} \mathrm{[ \% ]}$ & $\mathrm{Cr}$ [\%] & $\mathrm{Ni}$ [\%] & $\mathrm{P}$ [\%] & $\mathrm{S}$ [\%] & $\mathrm{N}$ [\%] & Fe [\%] \\
\hline 0.020 & 0.62 & 1.83 & 18.14 & 8.02 & 0.033 & 0.029 & 0.087 & Bal. \\
\hline
\end{tabular}

\subsection{Process parameters}

To achieve different shapes of marks, two laser-material interaction regimes were tested: surface heating and deep penetration heating. For the surface heating regime, the CMA optic was used and the temperature was held below the melting point. The circumferential speed was $38.7 \mathrm{~mm} / \mathrm{s}$ and the beam diameter on the specimen's surface was $51 \mu \mathrm{m}$. In the closed loop, a set-point voltage of $170 \mathrm{mV}$ was used (the target value of the PD's signal). During deep penetration heating, the temperature was higher than the evaporation temperature, which generates a keyhole formation similar to keyhole laser welding [8]. Optics without the CMA was used during this regime in order to achieve higher laser intensity. The circumferential speed was $38.7 \mathrm{~mm} / \mathrm{s}$ and the beam diameter was $22 \mu \mathrm{m}$. A set-point voltage of $170 \mathrm{mV}$ was used.

\subsection{Experiments and characterization}

The objective of the experiments was to compare the two regimes of laser-light interaction. Firstly, 81 marks were made with SH and 83 marks with DPH regime for observation a cross-section shape of marks and micro-hardness of marks. Secondly, 22 marks with SH and 22 marks with DPH regime were made for measuring average laser energy per mark, dynamic response at the beginning of laser processing and relative signal amplitude on LinACE ${ }^{\mathrm{TM}}$ sensor. And with third set of experiments, 3 marks with SH and 3 marks with DPH were inscribed over the surface with varying roughness to demonstrate characteristics of adaptive laser power control when disturbance of laser light absorption appears.

The depth and the width of marks were measured (on 81 marks for SH and on 83 marks for DPH) visually with an accuracy of $\pm 10 \mu \mathrm{m}$ from metallographic images and statistically analyzed. For both regimes the Vickers micro-hardness (using a $10 \mathrm{~kg}$ weight) was measured on 9 marks, where each mark was sampled at four points (Ta1...4 and Tb1...4), as shown in Figure 5. T-test was made in order to evaluate the statistical significance of the observed differences of measured micro-hardness. The chosen significance level was $5 \%$ and the null hypothesis was that the average of compared micro-hardness was equal. If the calculated $p$-value was below the threshold $(p=0.05)$, the null hypothesis was rejected.

The dynamic response was measured with an oscilloscope Keysight 3034A (350 MHz bandwidth, max. sample rate 4 GSa/s) and additionally analyzed in Matlab. To determine a steady state of PD signal, a tolerance of $\pm 5 \%$ was used. Rise time was determined as the time required for the response of PD signal to rise from beginning value $0 \%$ to $95 \%$ of its steady value.

The inscription quality was characterized using the magnetic LinACE ${ }^{\mathrm{TM}}$ sensor which consists of three main parts [1]. First part is a bias magnet providing permanent magnetic field defined by magnet geometry. Alternating sections of non-magnetic and magnetic region on specimen surface, which is close to magnet, result in modulation of this magnetic field. Linear arrays of Hall-effect elements are differentially connected to measure the gradient of amplitude of the modulation of magnetic field. The signals from Hall elements are conditioned in a microcontroller, which calculates the amplitude and the linear position. Relative amplitude $\left(A_{r}\right)$ was used for the characterization of the inscription quality. It represents the ratio between the measured amplitude with LinACE ${ }^{\mathrm{TM}}$ sensor above the marks made by laser processing and conventionally produced inscriptions by time consuming process of turning the grooves in high permeability carbon-steel and filling them with nonmagnetic material, i.e. copper. The depth-period of conventionally produced inscriptions was limited to $\mathrm{D} / \mathrm{P}=0.4$ due to the shape of the tool and the technology of further filling process, while the width-period ratio was set to $\mathrm{W} / \mathrm{P}=0.8$. The distance between the reference magnetic sensor and the specimens was set to $290 \mu \mathrm{m}$ with vertical micrometer drive (Thorlabs PT1/M) which has designated accuracy \pm 2 $\mu \mathrm{m}$. Positional noise was calculated as the standard deviation of 1000 linear position measurements with the magnetic LinACE ${ }^{\mathrm{TM}}$ sensor at the same location.

\section{EXPERIMENTAL RESULTS}

\subsection{Metallographic and micro-hardness examination}

The typical cross-sections of a mark made by laser surface heating are semi-circular, while they are U-shaped in the case of deep-penetration heating. They are shown in Figure 5. 
a)

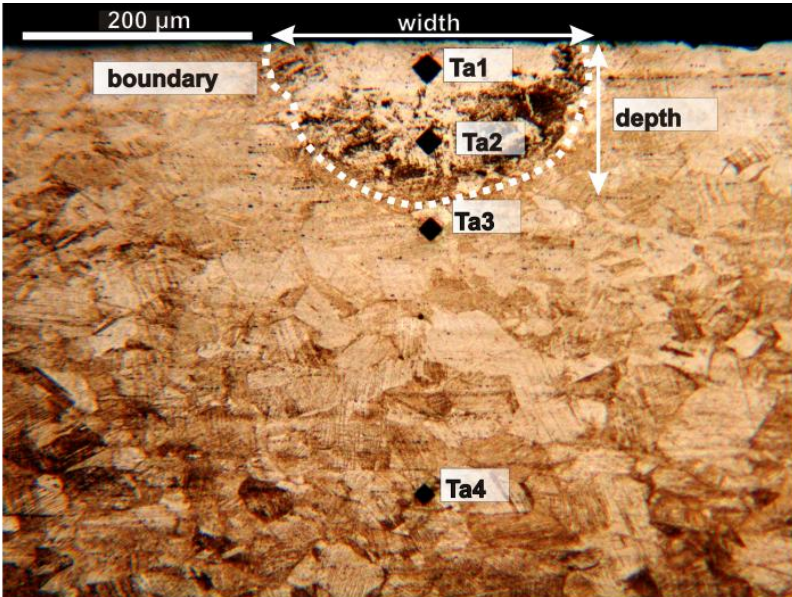

b)

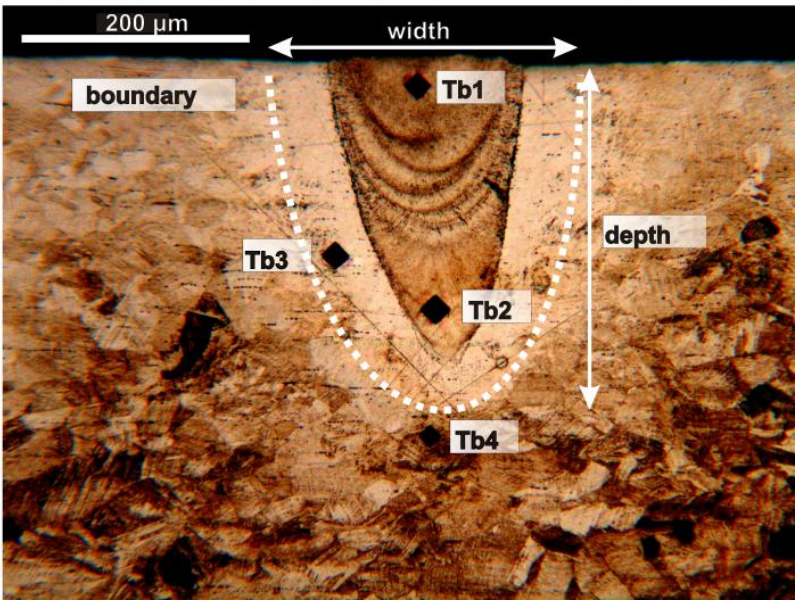

Figure 5: Typical cross-section shape of the mark made with laser surface heating (a) and with deep penetration heating (b).

In the case of surface heating, the mark region includes only a heat-affected zone (HAZ), and in the case of deep penetration heating, the mark also includes a melted area which is darker and more homogeneous comparing the surrounding material (see Figure 5b).

Deeper HAZ in the second regime is achieved mainly due to the keyhole formation, which enables an efficient laser light propagation deep under the specimen surface. Consequently much higher absorption of the laser light is achieved in the keyhole (approximately $98 \%$ ) as compared to the surface absorption (approximately 30\%) $[9,10]$. The high absorption in the keyhole is due to its light-trapping geometry and the plasma's appearance. This plasma has positive effects until it is trapped inside the keyhole. Otherwise, the light absorption appears above the specimen and, consequently, the heating area is defocused, which leads to process oscillations [7,11,12]. To prevent this effect, the system uses an air cross-jet (see Figure 4), which deflects the vapor and plasma plume away from the laser beam.

Table 2: Widths and depths of marks made with surface heating and deep penetration heating

\begin{tabular}{|l|l|l|l|l|l|}
\hline & $\begin{array}{l}\text { Surface } \\
\text { heating SH }\end{array}$ & $\begin{array}{l}\text { Deep penetration } \\
\text { heating } \mathrm{DPH}\end{array}$ & $\begin{array}{l}\mathrm{DPH} / \mathrm{SH} \text { ratio } \\
(\%)\end{array}$ & \multicolumn{2}{|l|}{ t-Test (H0: average SH = average $\mathrm{DPH})$} \\
\cline { 4 - 6 } & & & \multicolumn{2}{l|}{ p-value } & $\mathrm{H}_{0}$ \\
\hline $\begin{array}{l}\text { Width of marks } \\
\sigma_{\text {width }}\end{array}$ & $\begin{array}{l}354 \mu \mathrm{m} \\
35 \mu \mathrm{m}(\mathrm{N}=81)\end{array}$ & $\begin{array}{l}398 \mu \mathrm{m} \\
38 \mu \mathrm{m}(\mathrm{N}=83)\end{array}$ & $112 \%$ & $0.47 \cdot 10^{-12}$ & rejected \\
\hline $\begin{array}{l}\text { Depth of marks } \\
\sigma_{\text {depth }}\end{array}$ & $\begin{array}{l}363 \mu \mathrm{m} \\
16 \mu \mathrm{m}(\mathrm{N}=81)\end{array}$ & $\begin{array}{l}337 \mu \mathrm{m} \\
43 \mu \mathrm{m}(\mathrm{N}=83)\end{array}$ & $207 \%$ & $0.83 \cdot 10^{-61}$ & rejected \\
\hline
\end{tabular}

Numerical results of measured width and depth of marks are presented in table 2. The marks made with the laser surface heating have a more uniform depth (see $\sigma_{\text {depth }}$ in Table 2) than the marks made with the deep penetration heating. On the other hand, deep penetration heating results in a $207 \%$ higher average depth $(p<0.05)$ and a $112 \%$ wider cross-section compared to surface heating $(p<0.05)$. 

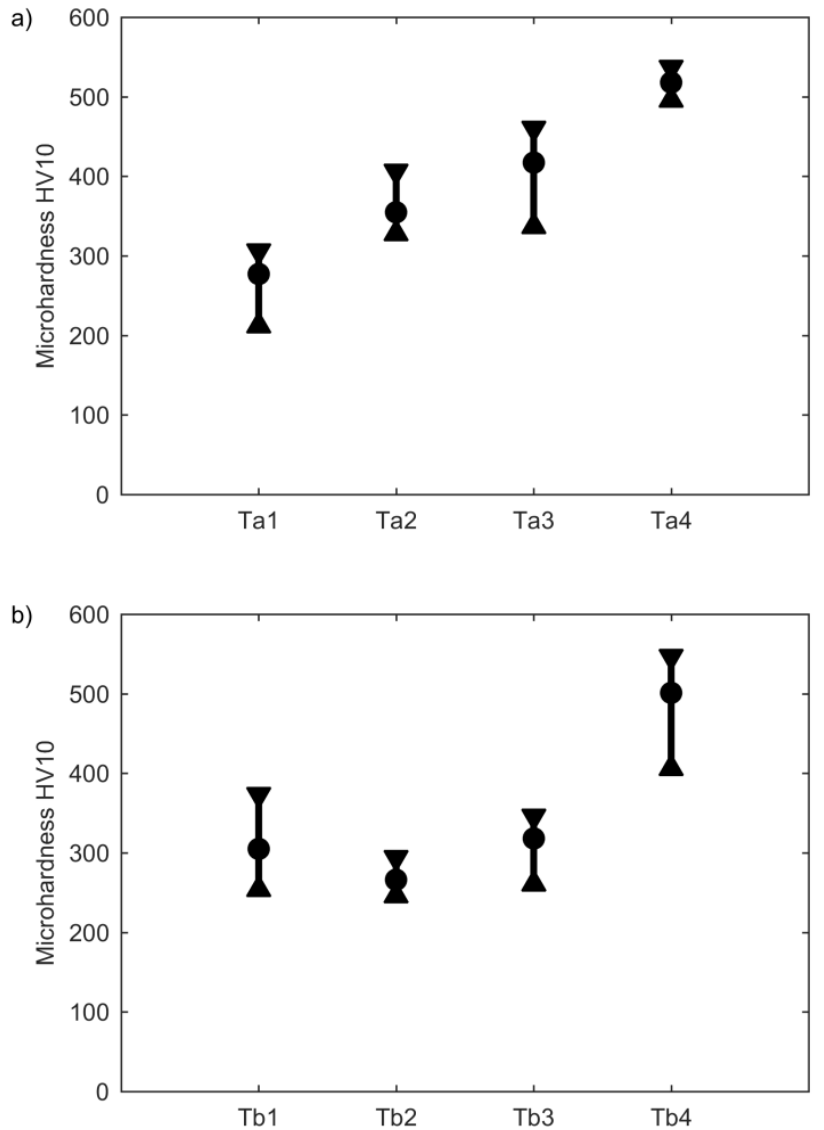

Figure 6: Micro-hardness at different locations for the marks inscribed by the surface heating (a) and the deep penetration heating regimes (b). See Figure 5 for the measuring locations.

Table 3: Micro-hardness of marks

\begin{tabular}{|l|c|c|c|c|c|}
\hline & \multirow{2}{*}{$\begin{array}{c}\text { SH average micro- } \\
\text { hardness }\end{array}$} & \multirow{2}{*}{$\begin{array}{c}\mathrm{DPH} \text { average micro- } \\
\text { hardness }\end{array}$} & \multirow{2}{*}{$\begin{array}{c}\text { SH/DPH } \\
\text { ratio }\end{array}$} & & \multicolumn{2}{|c|}{ t-Test $\left(\mathrm{H}_{0}\right.$ : average micro-hardness are the } \\
\cline { 5 - 6 } & & p-value & $\mathrm{H}_{0}$ \\
\hline $\begin{array}{l}\text { Near } \\
\text { surface }\end{array}$ & $\mathrm{Ta} 1=277 \mathrm{HV} 10$ & $\mathrm{~Tb} 1=305 \mathrm{HV} 10$ & $/$ & 0.12 & accepted \\
\hline $\begin{array}{l}\text { Bottom of } \\
\text { the mark }\end{array}$ & $\mathrm{Ta} 2=355 \mathrm{HV} 10$ & $\mathrm{~Tb} 2=266 \mathrm{HV} 10$ & 1.25 & $0.38 \cdot 10^{-6}$ & rejected \\
\hline $\begin{array}{l}\text { Near } \\
\text { boundary }\end{array}$ & $\mathrm{Ta}=417 \mathrm{HV} 10$ & $\mathrm{~Tb} 3=318 \mathrm{HV} 10$ & 1.31 & $0.44 \cdot 10^{-4}$ & rejected \\
\hline $\begin{array}{l}\text { Base } \\
\text { material }\end{array}$ & $\mathrm{Ta} 4=518 \mathrm{HV} 10$ & $\mathrm{~Tb} 4=501 \mathrm{HV} 10$ & $/$ & 0.24 & accepted \\
\hline
\end{tabular}

With comparing the micro-hardness near the surface of the mark for both regimes, we cannot conclude that average micro-hardness differ significantly (see Figure 6 and Table 3). The same conclusion can be made for base material which means that it is unaffected by laser processing regime. On the other hand, the average of micro-hardness at bottom of the marks made with SH (Ta2) is 1.25 times harder than bottom of the marks made with DPH regimes (Tb2). Similar ratio (1.31) can be observed at near boundary points (Ta3 and Tb3). The average of the melted part (Tb1) of the marks made with the deep penetration heating is softer than the base material (Tb4) by approximately $39 \%\left(p=0.25 \cdot 10^{-7}\right)$. Near the surface (Ta1), the marks made with the laser surface heating have an approximately $47 \%\left(p=0.45 \cdot 10^{-10}\right)$ lower micro-hardness compared to the base material.

\subsection{Average laser energy per mark and heat accumulation}

Figure 7 shows the laser energy per mark that is needed for the inscription. In case of SH the energy per mark is more than 4-times higher than at DPH. In order to maintain the constant transformation temperature inside the illuminated region, laser energy decreased by $14 \%$ (from $230 \mathrm{~J}$ to $197 \mathrm{~J}$ ) in the case of 
$\mathrm{SH}$. In the case of DPH, laser energy decreased less than $0.5 \%$ (from $45.5 \mathrm{~J}$ to $43.5 \mathrm{~J}$ ). This indicates that the second regime is far less sensitive to heat accumulation which saves approximately $450 \%$ of energy compared to $\mathrm{SH}$, and leads to better position accuracy of marks due to lower thermal expansion.

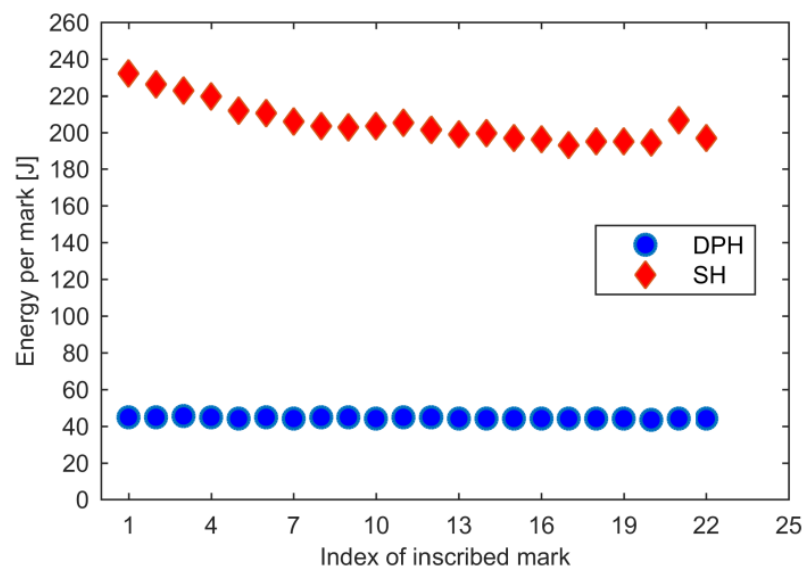

Figure 7: Incoming laser-beam energy per mark during the inscribing with surface heating and deep penetration heating regime. In the case of $\mathrm{SH}$, energy gradually decreased from $233 \mathrm{~J}$ to $197 \mathrm{~J}$ and in the case of DPH, energy slowly decreased from $45.5 \mathrm{~J}$ to $43.5 \mathrm{~J}$.

\subsection{Dynamics of laser power regulation}

At the beginning of inscribing with the SH regime, the laser power reaches the limit of experimental system at $400 \mathrm{~W}$ (see Figure 8) which causes a longer rising time and steady state time of PD signal compared to the DPH regime, where the limit was not achieved. The effect of heat accumulation during the sequential inscribing of 22 marks can be observed while constantly dropping the steady state time from $44.9 \mathrm{~ms}$ to $14.8 \mathrm{~ms}$ in the case of SH. In the case of $\mathrm{DPH}$, this effect cannot be recognized in the same way because the steady state time varies from $6 \mathrm{~ms}$ to $5 \mathrm{~ms}$. In the case of SH, the steady state time and rising time have the same value (see Figure $8 \mathrm{a}$ ) because there was no oscillation of the PD signal present as there was with DPH (see Figure $8 \mathrm{~b}$ ). The rising time in the case of DPH was below $0.05 \mathrm{~ms}$, which is approximately 300 -times better than in the case of $\mathrm{SH}$.

When inscribing the mark on the surface with varying roughness in the SH regime with closed-loop regulation, significantly smaller laser power was required on the surface with a higher roughness (see Figure 9a) to successfully keep the PD signal in a desired state. In the case of the DPH regime (see Figure 9b), the roughness disturbance cannot be observed from the laser power response. This can indicate that surfaces with higher roughness have a higher absorption of laser light when worked in $\mathrm{SH}$ regime and have no effect on absorption when worked in DPH regime.

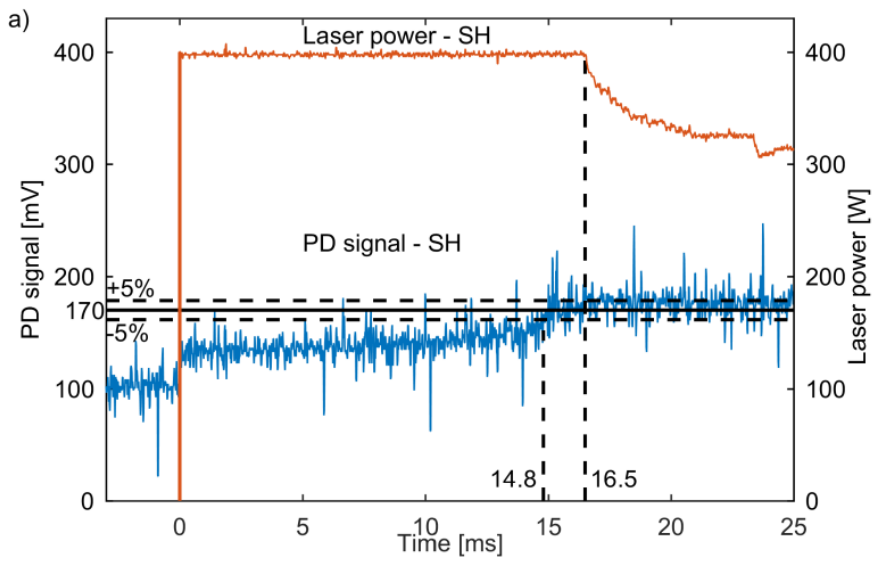




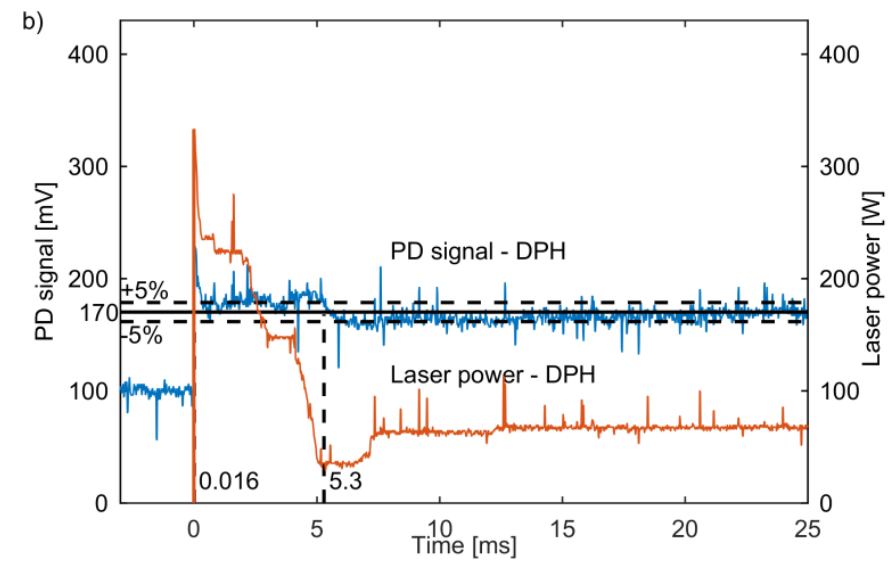

Figure 8: Typical responses of the laser power and of the PD signal at the beginning of inscribing with SH a) and with DPH b).
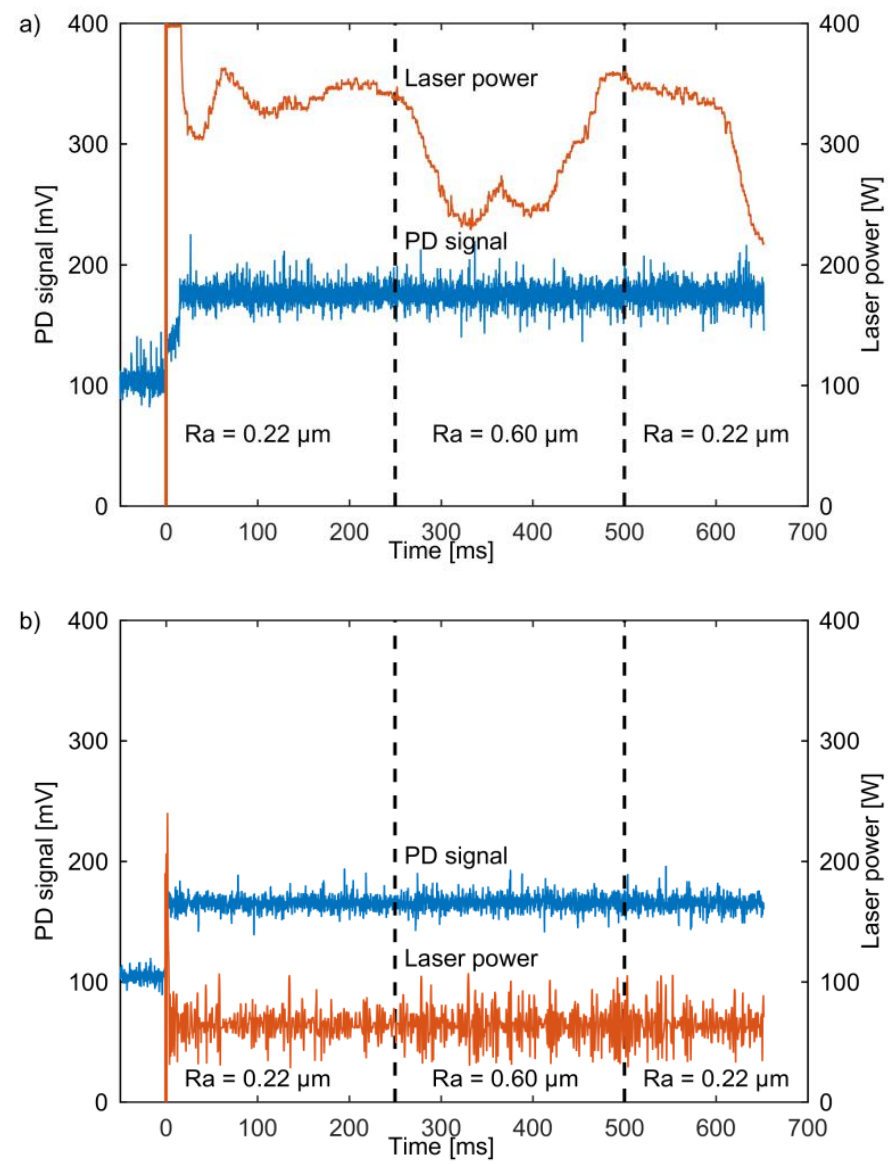

Figure 9: Typical PD and laser-power signals during the inscribing with the regime of surface heating a) and with the deep penetration heating $b$ ) on surfaces with different levels of roughness.

\subsection{Relative amplitude (Ar) comparison and positional noise with LinACE ${ }^{\mathrm{TM}}$ sensor}

The average of relative amplitude over all 22 marks was, in the case of SH, approximately $99.2 \%$ and in the case of DPH, $113.9 \%$. From Figure 10 it can be seen that in both cases, the relative amplitude is stable within $\pm 5 \%$. Positional noise in the case of SH was $3.14 \mu \mathrm{m}$ and in the case of DPH 2.68 um which indicate more stable position measurements. 


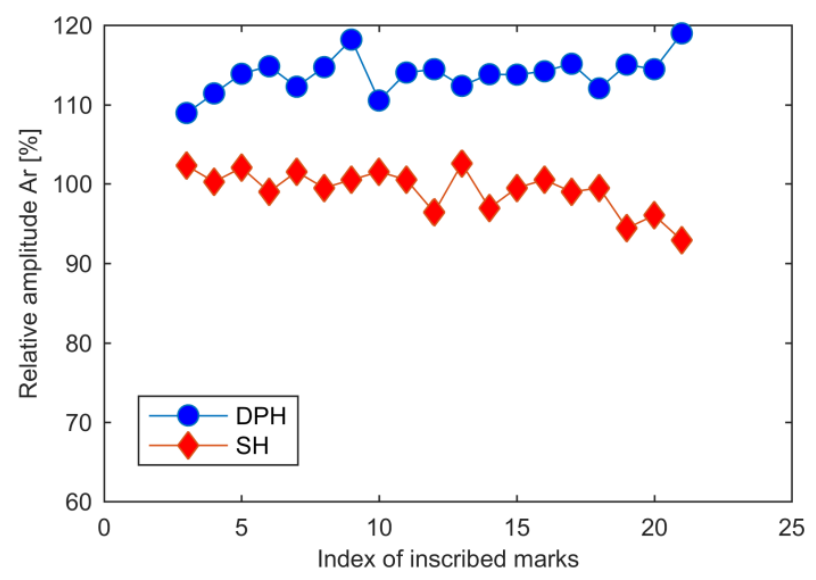

Figure 10: Relative amplitude in case of SH (red) and in case of DPH (blue) regime.

\section{Discussion}

Contours on the Figure 3 represent iso-amplitudes lines which are almost vertical when D/P ratio is high enough (>0.8). This means that further deepening of the marks does not improve amplitude response. Theoretically, U-shaped marks have $15 \%$ higher maximum amplitude in contrast to the semi-circular marks. The advantage of the semi-circular marks is in a wider range $(0.7 \mathrm{~W} / \mathrm{P}-0.9 \mathrm{~W} / \mathrm{P})$ of its maximum amplitude. Even if the width of marks matched the period, approximately $67 \%$ of its maximum amplitude remained. In contrast, the amplitude of U-shaped marks at W/P over 0.9 rapidly decreases. Very similar results have been observed in experiments where semi-circular marks had been fabricated with SH, or, alternatively, U-shaped marks with DPH laser processing. Above the marks made with a SH regime, the amplitude of signal on LinACE ${ }^{\mathrm{TM}}$ sensor was, on average, $15 \%$ lower and the positional noise was bigger for $17 \%$ than in the case of DPH (see Figure 10). This means that positional results in the case of SH would have higher uncertainty which lower the performance of encoder system. From metallographic pictures on Figure 5 it could be seen, that the width and the depth of marks are slightly smaller than the theoretically optimum which was found by numerical investigation (Figure 3). The average of the experimental width of marks in case of SH is $0.60 \cdot \mathrm{P}$ and in case of DPH the width is 0.66 . P which is around $17 \%$ less than the theoretical optimum. The laser parameters for this work for SH was defined by previous experiments described in [1] where optimization of parameters was not focused only to amplitude but also to minimizing the surface melting of marks [4]. Laser parameters for DPH were chosen by compromising the highest amplitude response on magnetic sensor at lower laser power for better costeffectiveness of the process.

Besides the amplitude of the signal, there are also other important parameters for comparison between these two regimes. Micro-hardness examinations have shown very similar behavior for both regimes with $25 \%$ harder bottom of the marks in the case of SH. We can see that in both cases micro-hardness rises from the surface of the mark, across the mark to the base material (Figure 6). The changing of hardness on the surface is not optimal in the light of tribology and higher is difference in micro-hardness between two neighbor regions higher is notch effect. This could decrease fatigue life, but with an additional coating such as hard chrome or pulsed plasma nitriding [4] this effect can be minimized.

Additionally, according to the Figure 7, significantly lower laser power is needed for DPH regime (4.5-times lower) comparing to the SH regime. A low amount of laser energy per mark deposited into the specimen leads to a more stable process and ensures better positional accuracy of each mark during laser processing for magnetic inscription.

Due-to laser power limitation of used system ( $400 \mathrm{~W}$ ), and a smaller absorption of laser light, the dynamic response at the beginning of laser processing was longer and more unstable in the case of SH (see Figure 8). However, when the process is stable, the laser system of SH regimes can perfectly react to a disturbance such as different roughness (see Figure 9a). In the case of DPH, roughness variations cannot be recognized as a disturbance (see Figure $9 \mathrm{~b}$ ) which is mainly due to higher absorption of laser light in the keyhole $[9,10]$.

The chosen period between two marks in this work was $0.60 \mathrm{~mm}$ which is the smallest period for detecting the position with magnetic LinACE ${ }^{\mathrm{TM}}$ sensor. With smaller periods, higher encoder resolution could be achieved, but on the other side the distance between the carrier of information (magnetic inscription on steel shaft) and the magnetic sensor is decreased, leading to difficult implementation of such encoders to different applications. However, also shorter period lengths could be produced with laser-based magnetic micro-inscription. The current experimental system can focus laser beam down to diameter of $11.2 \mu \mathrm{m}$, which is the major limiting dimension for further minimizing of the period between marks. However laser beam speed and power should be optimized again in such case.

\section{Conclusions}


Numerical results show that marks with $\mathrm{D} / \mathrm{P}>0.8 \cdot \mathrm{P}$ at $\mathrm{W} / \mathrm{P}=0.8 \cdot \mathrm{P} \pm 0.05 \cdot \mathrm{P}$ provide the best amplitude response for $\mathrm{U}$-shape marks. Marks could be deeper than 0.8.P at the same width but this would not improve the amplitude response. From the theoretical limitation semicircular marks could not reach depths larger than 0.5.P which is the main reason for lower amplitude response. Higher amplitude response of magnetic sensor can improve the precision of position measurement by a magnetic encoder which could be integrated into linear actuators with an in-axis measurement capability.

U-shaped cross-section of the marks with optimum depth and width according to period of marks can be achieved by a laser-based deep penetration heating (DPH) regime. Compared to the surface heating regime, the DPH enables more repeatable local microstructure transformation for magnetic inscription. It requires less laser energy, the process is more stable, it is insensitive to variation of surface roughness, it has a faster starting time and, most importantly, we measured higher average relative amplitude with the LinACE ${ }^{\mathrm{TM}}$ sensor. From all these facts, the DPH regime would appear to be a better choice for making magnetic inscription than $\mathrm{SH}$.

\section{ACKNOWLEDGEMENTS}

This research was supported by the Ministry of Education, Science and Sport, Slovenia, under grants L2-8183, P2-0392, and RLS Merilna tehnika d.o.o.

\section{References}

[1] Pogačar M, Kogej P, Možina J, Jezeršek M. Adaptive laser-based local transformations of the magnetic properties in austenitic stainless steel using optical feedback. Int J Adv Manuf Technol 2017;91:3225-31. doi:10.1007/s00170-017-9997-6.

[2] Ara K, Yagi H, Ikeda H, Sugiyama Y, Oomura T, Moriyasu M, et al. Formation of magnetic grating on steel plates by electron/laser beam irradiation. IEEE Trans Magn 1989;25:3830-2. doi:10.1109/20.42447.

[3] Sivec M. LinACE in-axis absolute linear encoder. vol. 2013, Nürnberg: 2013, p. 149-51. doi:DOI 10.5162/sensor2013/A7.2.

[4] Leskovšek V, Godec M, Kogej P. Strengthening via the Formation of Strain-Induced Martensite and the Effects of Laser Marking on the Microstructure of Austenitic Stainless Steel. Metall Mater Trans A 2014;45:2819-26. doi:10.1007/s11661-014-2213-5.

[5] Kogej P, Jezeršek M, Možina J, Babnik A. Apparatus and method for writing a pattern in a substrate. EP2714414 B1, $2012 ., 2015$.

[6] Dolsak G. Magnetic encoder apparatus. US8878526 B2, 2014.

[7] Zhang M, Chen G, Zhou Y, Li S. Direct observation of keyhole characteristics in deep penetration laser welding with a $10 \mathrm{~kW}$ fiber laser. Opt Express 2013;21:19997-20004. doi:10.1364/OE.21.019997.

[8] Mrňa L, Šarbort M, Řeřucha Š, Jedlička P. Correlation between the Keyhole Depth and the Frequency Characteristics of Light Emissions in Laser Welding. Phys Procedia 2013;41:469-77. doi:10.1016/j.phpro.2013.03.103.

[9] Steen W, Mazumder J. Laser Material Processing. 4th ed. London: Springer-Verlag; 2010.

[10] Kannatey-Asibu E. Frontmatter. Princ. Laser Mater. Process., John Wiley \& Sons, Inc.; 2009, p. i-xxvi. doi:10.1002/9780470459300.fmatter.

[11] Bardin F, Morgan S, Williams S, McBride R, Moore AJ, Jones JDC, et al. Process control of laser conduction welding by thermal imaging measurement with a color camera. Appl Opt 2005;44:6841-8. doi:10.1364/AO.44.006841.

[12] Luo Y, Tang X, Lu F, Chen Q, Cui H. Spatial distribution characteristics of plasma plume on attenuation of laser radiation under subatmospheric pressure. Appl Opt 2015;54:1090-6. doi:10.1364/AO.54.001090. 